\title{
Study on the Properties of Ni-Zn Ferrites Prepared by Using Nano-Size $\mathrm{ZnO}$
}

\author{
Jiwei Fan ${ }^{*}$, Zhihui Zhang ${ }^{b}$, Huijun Zhao ${ }^{c}$, Xiaoli Zhang ${ }^{\mathrm{d}}$, Zhenguo Zhang ${ }^{\mathrm{e}}$ \\ School of Materials and Chemical Engineering, Zhongyuan University of Technology, \\ Zhengzhou, 450007, China \\ ${ }^{* a}$ Corresponding author, email:jeff51@163.com; bemail: 719822137@qq.com; \\ cemail: zhj@zzti.edu.cn; 'email: karer2004@163.com; eemail:zhangzg1969@163.com
}

Keywords: Ni-Zn Ferrite, Power loss, Permeability, Resistivity, Microstructure

\begin{abstract}
The present work reported and discussed the results of investigation of employing nano- $\mathrm{ZnO}$ and general $\mathrm{ZnO}$ (AR grade) to prepare $\mathrm{Ni}_{0.5} \mathrm{Zn}_{0.5} \mathrm{Fe}_{2} \mathrm{O}_{4}$ ferrites. The samples were prepared by using conventional ceramic processing route and sintered between $1150-1250^{\circ} \mathrm{C}$. The comparison of sintered samples made by employing nano- $\mathrm{ZnO}$ and made by employing general $\mathrm{ZnO}$ powder shows that the use of nano- $\mathrm{ZnO}$ could increase the chemical activity of starting materials, improve the densification and homogeneity of sintered bodies, enhance the electrical and magnetic properties of $\mathrm{Ni}-\mathrm{Zn}$ ferrites.
\end{abstract}

\section{Introduction}

$\mathrm{Ni}-\mathrm{Zn}$ ferrites are used widely as magnetic devices in telecommunication and electronic industries because they possess excellent magnetic properties suitable for working at high frequency[1-4].. Particularly, they can be produced by simple ceramic processing without the requirement of controlling sintering atmosphere.

It is well known that the properties of ferrite are mainly controlled by composition, starting materials and employed processing method. Recently, many commercial nano-chemicals have been produced with the development of nanotechnology. However, little systematic study has been carried out on the effects of using nano-chemicals on the processing of Ni-Zn ferrites, especially their magnetic and electrical properties. The present work shows the results of investigation on the influence of employing nano- $\mathrm{ZnO}$ in a typical $\mathrm{Ni}-\mathrm{Zn}$ ferrite composition, comparison of its sintered density, resistivity, power loss and microstructure with the Ni-Zn ferrites produced by using general chemicals.

\section{Experimental Procedures}

Sample Preparation. The ferrite samples used in this study were based on a typically commercial formula: $\mathrm{Ni}_{0.5} \mathrm{Zn}_{0.5} \mathrm{Fe}_{2} \mathrm{O}_{4}$. All starting materials were analytic grade oxides, the average particle size of nano- $\mathrm{ZnO}$ is about $60 \mathrm{~nm}$. They were mixed in deionised water with agate balls for 20 hours by ball milling. After drying, granules were obtained by passing the dried powders through a screen having an aperture mesh of nominally $0.3 \mathrm{~mm}$. The small disc shape samples $(12 \mathrm{~mm}$ diameter, $3 \mathrm{~mm}$ height.) and the toroid samples (25mm outside diameter, $18 \mathrm{~mm}$ inside diameter, and $3 \mathrm{~mm}$ height) were pressed by a uniaxial press at $80 \mathrm{MPa}$. The samples were sintered at temperatures over the range $1150-1250^{\circ} \mathrm{C}$ for 2 hours in air, with both heating and cooling rates at $3^{\circ} \mathrm{C} / \mathrm{min}$. The samples prepared by general chemicals were designated as $\mathrm{C}$ samples, and the samples prepared by nano- $\mathrm{ZnO}$ were designated as $\mathrm{N}$ samples.

Characterization. The sintered densities of the samples were determined according to the mass and volume of sample. Before electrical measurements, sliver electrodes were applied to both sides of the disc samples. The resistances of disc samples were determined by using a LCR meter (Victor VC9018). The resistivities were computed out according to the measured resistances and the 
geometry of discs. The power loss of sintered Ni-Zn ferrite toroids were determined by using two windings (both primary and secondary coils are 50 turns) and sample geometries by an ac magnetic property measuring equipment (TY-2000A). The testing flux density is $0.08 \mathrm{~T}$ and the testing frequencies are $30 \mathrm{kHz}$ and $50 \mathrm{kHz}$ respectively. The microstructures of samples were examined by using a scanning electron microscope (JSM-6360LV) equipped with energy dispersive spectrometer (EDS).

\section{Results}

Sintered Density. Table 1 shows the comparison of sintered densities of samples at different sintering temperatures. It indicates that the samples prepared by nano- $\mathrm{ZnO}(\mathrm{N}$ sample) could achieve higher densities at all sintering temperatures. Obviously, the high sintering temperature enhances the densification of Ni-Zn ferrites.

Table 1 The sintered densities of samples

\begin{tabular}{cccc}
\hline Sintering Temperature $\left({ }^{\circ} \mathrm{C}\right)$ & 1150 & 1200 & 1250 \\
\hline Sintered Density for C Samples $\left(\mathrm{g} / \mathrm{cm}^{3}\right)$ & $3.57 \pm 0.01$ & $4.21 \pm 0.02$ & $4.35 \pm 0.02$ \\
\hline Sintered Density for N Samples $\left(\mathrm{g} / \mathrm{cm}^{3}\right)$ & $3.62 \pm 0.01$ & $4.22 \pm 0.01$ & $4.42 \pm 0.02$
\end{tabular}

Resistivity. Fig.1 shows the resistivities of Ni-Zn ferrite samples as a function of sintering temperatures. It is interesting to see that the resistivities of $\mathrm{N}$ samples decrease with the increase of sintering temperature, but the resistivities of general $\mathrm{Ni}-\mathrm{Zn}$ ferrites have the maximum value obtained at the samples sintered at $1200^{\circ} \mathrm{C}$. The trend of the resistivities indicates that the $\mathrm{N}$ samples can achieve the higher resistivities than those $\mathrm{C}$ samples, which could be due to the effect of using nano- $\mathrm{ZnO}$.

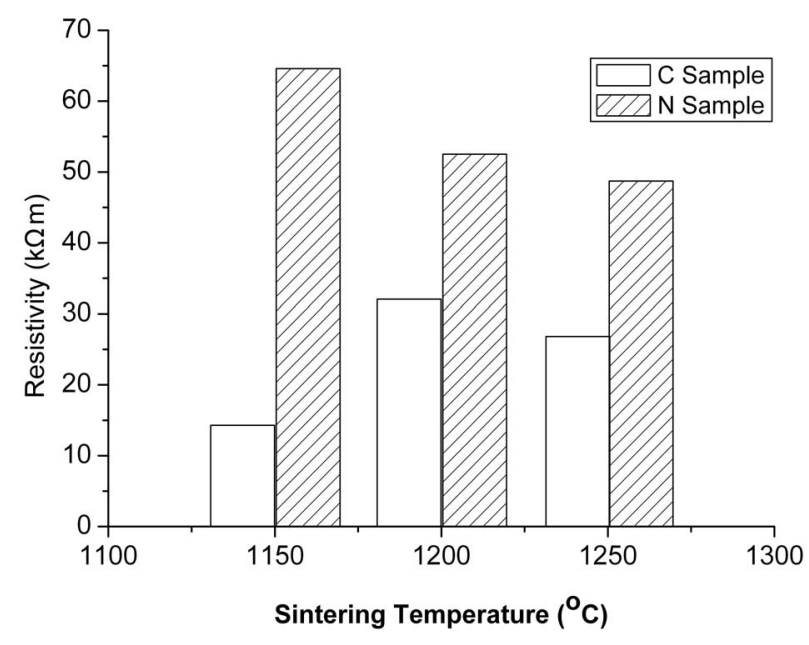

Fig. 1 The resistivity of samples

The permeability and power loss. The permeability and power loss are two of important magnetic properties for soft ferrites. The permeability and power loss of both Ni-Zn ferrite samples are shown in Table 2. It is obvious that the samples made by using nano- $\mathrm{ZnO}$ ( $\mathrm{N}$ samples) have higher permeability's than those of general samples. The testing frequencies were $30 \mathrm{kHz}$ and 50 $\mathrm{kHz}$ respectively. Furthermore, the samples sintered at higher temperature have higher values of permeability's. From Table 2, it can also be seen that the $\mathrm{N}$ samples have less power losses than those of $\mathrm{C}$ samples. The power losses of samples increased with higher sintering temperature. 
Table 2 The permeability and power loss of samples

\begin{tabular}{|c|c|c|c|c|c|c|c|c|}
\hline \multirow{2}{*}{} & \multicolumn{3}{|c|}{ Permeability $\mu_{\mathrm{m}}(\mathrm{mH} / \mathrm{m})$} & \multicolumn{3}{c|}{ Power Loss (W/Kg) } \\
\cline { 2 - 9 } & \multicolumn{2}{|c|}{$30 \mathrm{kHz}$} & \multicolumn{2}{|c|}{$50 \mathrm{kHz}$} & \multicolumn{2}{c|}{$30 \mathrm{kHz}$} & \multicolumn{2}{c|}{$50 \mathrm{kHz}$} \\
\hline Samples & $\mathrm{C}$ & $\mathrm{N}$ & $\mathrm{C}$ & $\mathrm{N}$ & $\mathrm{C}$ & $\mathrm{N}$ & $\mathrm{C}$ & $\mathrm{N}$ \\
\hline $\begin{array}{c}1150^{\circ} \mathrm{C} \\
\text { sintered }\end{array}$ & $0.46 \pm 0.01$ & $0.68 \pm 0.01$ & $0.45 \pm 0.01$ & $0.68 \pm 0.01$ & $20.8 \pm 0.1$ & $13.3 \pm 0.1$ & $33.0 \pm 0.2$ & $20.3 \pm 0.1$ \\
\hline $\begin{array}{c}1250^{\circ} \mathrm{C} \\
\text { sintered }\end{array}$ & $0.52 \pm 0.01$ & $0.75 \pm 0.01$ & $0.51 \pm 0.01$ & $0.74 \pm 0.01$ & $60.8 \pm 0.3$ & $51.8 \pm 0.2$ & $103.9 \pm 0.3$ & $88.3 \pm 0.2$ \\
\hline
\end{tabular}

Microstructure. The typical SEM micrographs of samples sintered at $1150^{\circ} \mathrm{C}$ are shown in Fig.2. It can be clearly seen that the grain size of $\mathrm{N}$ sample (Fig.2b) is more uniform and the sintered body looks denser, which may be due to the more chemical activity of nano- $\mathrm{ZnO}$. This is why the sintered density of $\mathrm{N}$ sample is higher than that of $\mathrm{C}$ sample. The roughly estimated average grain size is $1.1 \pm 1.6 \mu \mathrm{m}$ for $\mathrm{C}$ sample and $1.0 \pm 0.8 \mu \mathrm{m}$ for $\mathrm{N}$ sample.

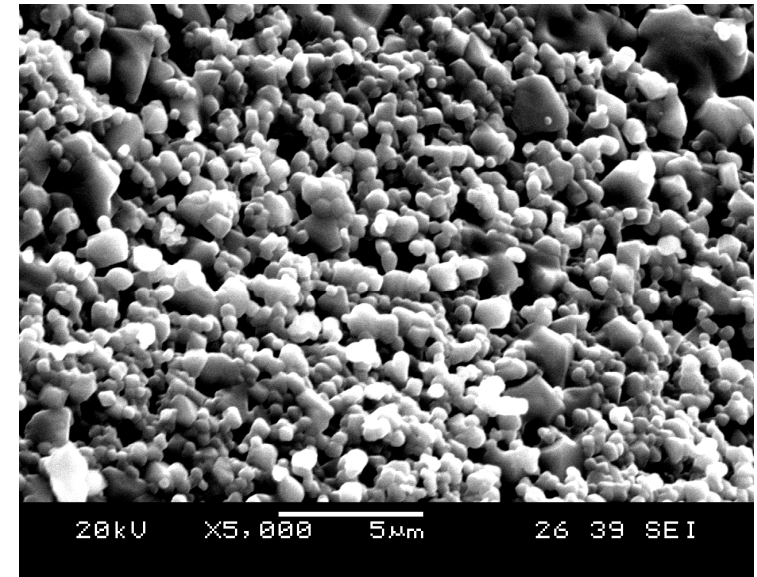

(a)

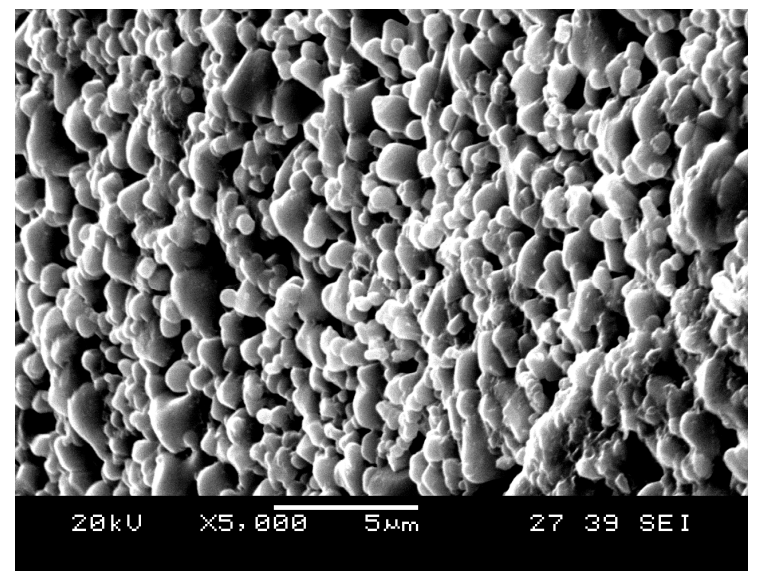

(b)

Fig. 2 Typical SEM micrographs of Ni-Zn ferrites sintered at $1150^{\circ} \mathrm{C}$, (a) C sample; (b) $\mathrm{N}$ sample

\section{Discussion}

The permeability and power loss are two of important magnetic properties for soft ferrites. Usually the influence factors for the permeability are formulation, staring materials, processing route and the resulting microstructure. If the formulation and processing route are same, the ferrites with larger and more uniform grain size have higher permeability.[4-7] In this experiment, the samples made by using nano- $\mathrm{ZnO}$ ( $\mathrm{N}$ samples) have similar grain size and better uniformity, these may be attributed to the higher chemical activity of nano- $\mathrm{ZnO}$ powder. Therefore, they have higher permeability than those of general samples. At higher sintering temperature, the higher permeability can be attributed to the larger average grain size.

Generally the power loss $\mathrm{P}_{\mathrm{L}}$ of ferrite materials consists of three components, i.e., the hysteresis loss $\mathrm{P}_{\mathrm{h}}$, eddy current loss $\mathrm{P}_{\mathrm{e}}$, and residual loss $\mathrm{P}_{\mathrm{r}}$. Since the residual loss $\mathrm{P}_{\mathrm{r}}$ is only of importance at very low induction levels or at high frequency $(>500 \mathrm{kHz})[8-10]$, the power loss can be expressed as following:

$$
\mathrm{P}_{\mathrm{L}}=\mathrm{P}_{\mathrm{h}}+\mathrm{P}_{\mathrm{e}}
$$

For the materials operating at typical frequencies $\mathrm{P}_{h}$ and $\mathrm{P}_{\mathrm{e}}$ can be given as $[8,9,11]$ :

$$
\begin{aligned}
& \mathrm{P}_{\mathrm{h}}=\mathrm{C}_{\mathrm{h}} \mathrm{B}^{3} \mathrm{f} \\
& \mathrm{P}_{\mathrm{e}}=\mathrm{C}_{\mathrm{e}} \mathrm{B}^{2} \mathrm{fD}^{2} / \rho
\end{aligned}
$$

where $C_{h}$, and $C_{e}$, are the coefficients for hysteresis loss and eddy current loss, respectively, $B$ is 
flux density (Tesla), $\mathrm{f}$ is frequency $(\mathrm{kHz}), \mathrm{D}$ is the average grain size $(\mu \mathrm{m})$ and $\rho$ is resistivity $(\Omega \mathrm{m})$. Combining (2) and (3), the power loss can be expressed as:

$$
\mathrm{P}_{\mathrm{L}}=\mathrm{P}_{\mathrm{h}}+\mathrm{P}_{\mathrm{e}}=\mathrm{C}_{\mathrm{h}} \mathrm{B}^{3} \mathrm{f}+\mathrm{CB}^{2} \mathrm{f}^{2} \mathrm{D}^{2} / \rho
$$

Since the testing flux density are fixed $(\mathrm{B}=0.08 \mathrm{~T})$, according to Equation $(4)$, it can be seen the influence factors to power loss are frequency $\mathrm{f}$, average grain size $\mathrm{D}$ and resistivity $\rho$. The power loss is proportional to $\mathrm{f}$, therefore the samples have higher power losses at higher frequency. Moreover, since the average grain sizes for both samples are similar, therefore, the resistivity plays important role in power loss. The samples made by using nano-ZnO ( $\mathrm{N}$ samples) have much higher resistivities than those of $\mathrm{C}$ samples (refer Fig.1), hence $\mathrm{N}$ samples have less power losses are quite reasonable.

\section{Conclusions}

The sintered density, resistivity, permeability and power loss of $\mathrm{Ni}_{0.5} \mathrm{Zn}_{0.5} \mathrm{Fe}_{2} \mathrm{O}_{4}$ ferrite are strongly affected by sintering temperature.

The comparison of sintered samples made by using nano- $\mathrm{ZnO}$ ( $\mathrm{N}$ samples) and general $\mathrm{ZnO}$ powder, the samples using nano-ZnO have higher sintered densities, resistivities and permeabilities, less power losses.

The use of nano- $\mathrm{ZnO}$ increased the chemical activity, improved the densification and homogeneity, and enhanced the electrical and magnetic properties of Ni-Zn ferrites.

\section{Acknowledgements}

The authors acknowledge the supports by the Natural Science Foundation of China (51072238).

\section{References}

[1] V. C. S. Diniz, D. A.Vieira, R. H. G. A. Kiminami, D. Cornejo, A. C. F. de M. Costa, 'Sintering of Ni-Zn Ferrite by Microwave Energy', Materials Science Forum, 2012, 727 - 728, 977-981

[2] R.V. Mangalaraja, S. Ananthakumar, P. Manohar, F.D. Gnanam, 'Initial permeability studies of $\mathrm{Ni}-\mathrm{Zn}$ ferrites prepared by flash combustion technique', [J]. Materials Science and Engineering, 2003, A355, 320-324

[3] B. P. Rao, A. M. A. Kumar, K. H. RAO, Y. L. N. Murthy, O. F. Caltun, I. Dumitruc, L. Spinu, 'Synthesis and magnetic studies of Ni-Zn ferrite nanoparticles', [J]. Journal of Optoelectronics and Advanced Materials, 2006, 8, $1703-1705$

[4] A. Goldman, 'Modern Ferrite Technology', 1990, New York, Van Nostrand Reinhold,

[5] J Fan, F.R.Sale, 'The Microstructures, Magnetic Properties and Impedance Analysis of Mn-Zn Ferrites Doped with B2O3', [J]. J.Eur.Ceram.Soc., 2000, 20, 2743-2751,

[6] J Fan, F.-K. Ng, F.R.Sale, 'Magnetic Properties and Microstructure of $\mathrm{SnO}_{2}$ doped $\mathrm{Mn}-\mathrm{Zn}$ Ferrites', [J]. Rare Metals, 2006, 25, Sup., 445-449,

[7] J Fan, W. Li, H. Zhao, X. Zhang, Z. Zhang, 'The Effects of Sintering Temperature on the Properties of Mg-Mn-Zn Ferrites', [J]. Advanced Materials Research, 2013, 680, 31-34

[8] J. Fan, F. R. Sale, 'Analysis of Power Loss on Mn-Zn Ferrites Prepared by Different Processing Routes', [J]. IEEE Transactions on Magnetics, 1996, 32, 4854-4856

[9] E. C. Snelling and A. D. Giles, 'Ferrites for Inductors and Transformers', 54-62, 1983, Philips Research Laboratory, Redhill, Surry, England

[10] T. Mochizuki, I. Sasaki and M.Torii, 'Mn-Zn ferrites for $400-600 \mathrm{kHz}$ switching power supplies,' in 'Advances in Ceramics', vo1.16, (Ed. by F. Y. Wang), 487-492, 1985, The American Ceramic Society, Columbus, USA..

[11] Th. G. W. Stijntjes and J. J. Roelofsma, 'Low-loss power ferrites for frequencies up to 500 kHz,' in 'Advances in Ceramics', vo1.16, (Ed. by F. Y. Wang), 493-500, 1985, The American Ceramic Society, Columbus, USA 